\title{
QUANTITATIVE ANALYSIS OF MEIOTIC CONFIGURATIONS IN TIP STERILE LINES OF HEXAPLOID WHEAT
}

\author{
Shahriar Zaman*, M. Abdul Mazid and Golam Kabir ${ }^{1}$ \\ Department of Genetic Engineering \& Biotechnology, University of Rajshahi, Rajshahi 6205 Bangladesh; \\ ${ }^{1}$ Prof. S. Alam Cytogenetics Laboratory, Department of Botany, University of Rajshahi, Rajshahi 6205, \\ Bangladesh \\ *Corresponding author (e-mail: szbobbie@gmail.com)
}

\begin{abstract}
In five tip sterile lines of hexaploid wheat (Kheri, Mexicani, Pavon-76, Seri-82 and Sonora-64) due to interchange of segments three types of meiotic configuration i.e. ring quadrivalent (oIV), chain quadrivalent (cIV) and trivalent plus univalent (III.I) were found at metaphase I. The observed and expected numbers of meiotic configurations in these translocated lines of wheat were found to following the equations based on normal pairing and non random distribution of chiasmata. Different configurations (oIV, cIV, III.I, oII, cII and I) were analyzed following Jackson and Murray's (1986) formula. The results revealed that $\chi^{2}$-values for the translocated heterozygotes showed to be fit with the expectation. Data showed good agreement between numbers of expected and observed meiotic configuration and all the lines were in fit to the Ho with $\mathrm{p}>0.05$.
\end{abstract}

Keywords: Meiotic configurations, tip sterility, hexaploid wheat.

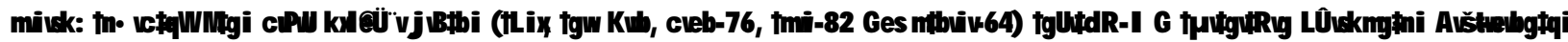

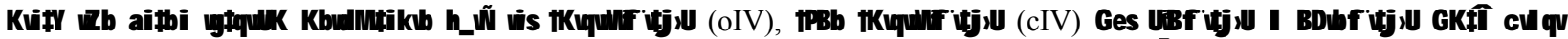

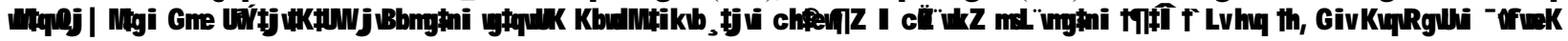

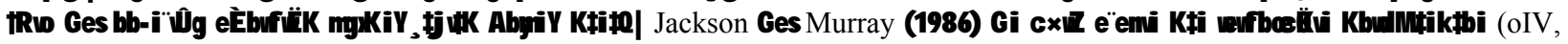

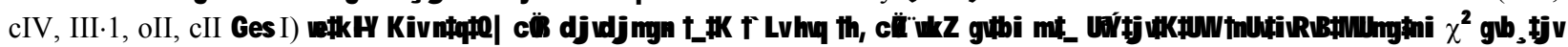

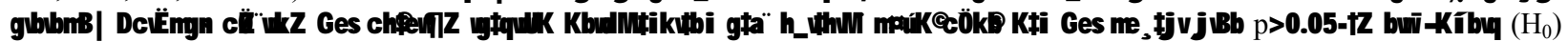
$\operatorname{msMLZ} \times$ XP

\section{Introduction}

Meiotic configurations are the apparent forms in which chromosome combinations become interpretative distinguishably at all stages. But due to variations in pairing, chiasma formation and orientation, same chromosomes can form different configurations at the same stages. Triticum aestivum L. is an allohexaploid and its pollen mother cells show always bivalent formation i.e. it acts as functionally diploid. But presence of quadrivalents in hexaploid wheat obviously indicates its different orientation of chromosomes during meiosis.

Occurrence of reciprocal translocation in wheat varieties has been mentioned by many workers (Baker and McIntosh, 1966; Coucoli and Skorda, 1969; Law and Worland, 1973; Baier et al., 1974; Vega and Lacadena, 1983; Perera et al., 1983; Lange et al., 1987; Primard et al., 1991). Among them Primard et al., (1991) found the variety Atlas 66 to show this unusual trait repeatedly generation after generation. Elliott (1985) reported configuration of three chromosomes instead of four when Atlas 66 was crossed with Wichita monosomic.
Heterozygous reciprocal translocation can change chiasma frequencies in other chromosomes in the same cell as a result of reduced crossing over in the translocation complex (Sybenga, 1975).These findings obviously claim a quantitative analysis of translocation heterozygote in hexaploid wheat.

\section{Materials and Methods}

The study was conducted in the Prof. S. Alam Cytogenetics Laboratory, University of Rajshahi during the growing seasons of 2004-2006 for studying meiotic configurations in normal line Kanchan and five apical tip sterile translocated varieties/lines of wheat namely Kheri, Mexicani, Pavon-76, Seri-82 and Sonora-64. All these studied plants were grown in earthen pots and the steps adopted are mentioned below:

Sampling of plants and collection of inflorescences: At least 10 plants for each of the six variety/lines were selected at random and from these plants inflorescences were collected between $8.30 \mathrm{a} . \mathrm{m}$. to $10.30 \mathrm{a} . \mathrm{m}$. for making observations meiotically. The inflorescences from each variety were fixed for 48 hours in Carnoy's solution (6 ethanol : 3 chloroform : 1 acetic acid) and 
then preserved in $70 \%$ ethanol and kept in a refrigerator till used.

Preparation of slides: For meiotic analysis with special emphasis on meiotic configuration and structural chromosomal changes the temporary slides were prepared from suitable anthers by the standard acetocarmine smear technique.

Analysis of meiotic configurations: For making quantitative analysis of meiotic configurations in translocated heterozygotes of wheat along with the normal line, the models and equations proposed by Jackson and Murray (1986) were followed. Here both normal synapses and crossing over, and the reciprocal translocations that affect the normal processes were considered. The chromosomes observed in the karyotypic analysis were either metacentric or submetacentric and thus, there was equal probability that a crossover may occur in either arm. Each bivalent and bivalent equivalent may also have the same opportunity to form chiasma.

In case of equations $\mathrm{P}$ value was considered for chiasma probability that was derived by dividing the average number of chiasma per bivalent by the maximum number expected, which was 2 in these models. The $\mathrm{Q}$ value was 1 - P. In both the normal non-random and random methods, chiasmata were allocated by binomial distribution. But in case of non-random method some of the terms were used, where $\mathrm{P}$ and $\mathrm{Q}$ replaced $\mathrm{p}$ and $\mathrm{q}$. Exponents of $\mathrm{p}$ represented the number of chiasmata and those of q lacked thereof. The following symbols were used in this study: oII $=\mathrm{a}$ two chiasmata quadrivalent; oIV $=\mathrm{a}$ four chiasmata bivalent; cII $=\mathrm{a}$ one chiasmata bivalent; $\mathrm{cIV}=\mathrm{a}$ three chiasmata quadric-valent; cIII.I = a two chiasmata trivalent and a univalent; $\mathrm{I}=\mathrm{a}$ univalent; $\mathrm{n}=$ the expected number of normal bivalents; and $\Sigma=$ the sign of summation.

According to normal pairing and non-random chiasma distribution models and equations as proposed by Jackson and Murray (1986) P value be greater than 0.5 and I be absent unless they were derived from a III.I configuration. All the homologous chromosomes were synapsed and the interchange formed a IV. Each II or its equivalent in a quadrivalent (IV) had a minimum of one and a maximum of two chiasmata. The translocation configuration with almost four equal arms might have 2, 3 or 4 chiasmata. These chiasmata initially were distributed in quadrivalent arms according to the binomial $(p+q)^{4}$. Thus, $p^{4}+4 p^{3} q^{1}$ $+6 p^{2} q^{2}+4 p^{1} q^{3}+q^{4}$ (based on allocated chiasma in four arms) were the distributions of 4 to 0 chiasmata in a random way. The $\mathrm{p}^{4}$ denoted a chiasma in each arm of the IV at pachytene and at diakinesis or metaphase-I yield a
oIV. Thus, it becomes $1\left(p^{4}\right)=$ oIV expected frequency. Similarly, $4\left(\mathrm{p}^{3} \mathrm{q}^{1}\right)$ represent a three chiasmata events so $4\left(\mathrm{P}^{3} \mathrm{Q}^{1}\right)=$ a cIV preliminary estimate.

However, the following equation for determining the number of expected diakinesis or metaphase-I configurations in a translocated heterozygote with almost equal sized chromosomes of metacentric or submetacentric type were used in this study. The equations are as follows: oIV $=\left(\mathrm{P}^{4}\right) \times\left[\mathrm{CI}-2 \mathrm{Q} \div \mathrm{P}^{3}(\mathrm{I}+\right.$ Q) $] \times$ No. of cells; cIV $=4\left(\mathrm{P}^{3} \mathrm{Q}^{1}\right) \times\left[\mathrm{CI}-2 \mathrm{Q} \div \mathrm{P}^{3}(\mathrm{I}+\right.$ Q)] x No. of cells; oII $=(n-2) \times(I-2 Q) \times$ No. of cells; cII $=$ No. of cells $\times(2 n)-(\Sigma$ chromosomes in oII + cIV $+\mathrm{oIV}) \times 0.5$; III.I $=4\left(\mathrm{P}^{2} \mathrm{Q}^{2}\right) \times$ No. of cells. It is not always predictable and this class may be included in the expected cII class with each expected III.I counted as equivalent to two chain bivalents. Any observed III.I configurations were multiplied by 2 and the result was added to the observed cII class). However, the equations were used based on complete synapses and a non-random distribution of 1 to 2 chiasmata per bivalent and 2 to 4 per quadrivalent.

On the contrary, the equations used for complete pairing and random distribution of 0 to 2 chiasmata/II and 2-4 chiasmata/IV are as follows: oIV $=\left(\mathrm{P}^{4}\right) \times$ No. of cells; cIV $=4\left(\mathrm{P}^{3} \mathrm{Q}^{1}\right) \times$ No. of cells; cIII $=4\left(\mathrm{P}^{2} \mathrm{Q}^{2}\right) \times$ No. of cells; oII $=\mathrm{P}^{2}(\mathrm{n}-2) \times$ No. of cells; cII $=4\left(\mathrm{P}^{1} \mathrm{Q}^{1}\right) \times$ No. of cells $+[2(P Q) \times(n-2) \times$ No. of cells $] ;$ and I $=2\left(Q^{2}\right)$ $\times \mathrm{n} \times$ No. of cells. These equations were used for random pairing of homologous arms always followed by a crossover and they were also used for determining all expected meiotic configurations in the cell samples.

\section{Results and Discussion}

In tip sterile lines of wheat with reciprocal translocated heterozygotes, the interchange of segments between two non-homologous chromosomes were found to produce a cross-shaped configuration of quadrivalent at diakinesis stage of meiosis. Three types of quadrivalent i.e. ring quadrivalent (oIV), chain quadrivalent (cIV) and trivalent plus univalent (III.I) were found clearly at metaphase-I. The different types of meiotic configurations in different translocated lines/varieties of wheat in the present study are given in Figs. 1-3 in the form of Camera lucida drawings for clear visualization. The observed and expected number of meiotic configurations in different translocated lines of wheat, where the equations are based on normal pairing and nonrandom distribution of chiasmata are presented in Table 1. Data for different meiotic configurations i.e. oIV, cIV, III.I, oII, cII and I were analyzed for normal pairing and 
non-random chiasma distribution following model and equations proposed by Jackson and Murray (1986). The results obtained from Table 1 revealed that $\chi^{2}$-values for all the translocated heterozygotes showed to be fit with the expectation. Therefore, the data (Table 1) showed good agreement between numbers of expected and observed meiotic configuration and all the plant samples were in a good fit to the Ho with $\mathrm{P}>0.05$.

The observed and expected numbers of meiotic configuration in different varieties of wheat where the equations were based on random pairing and/or chiasmata distribution are given in Table 2. The equations for random chiasmata distribution were used to determine the expected numbers but it differed significantly from those obtained with non-random chiasmata distribution. Therefore, the $\chi^{2}$-values for random expected numbers were not in fit with the expectation due to $\mathrm{P}<0.05$. In the present study, the expected number of meiotic configuration was determined by using both the nonrandom and random methods. The $\chi^{2}$-values for nonrandom expected number had a fit with $\mathrm{P} \geq 0.50$ and random expected number had a fit with $\mathrm{P}<0.05$. Therefore, non-random expected number of meiotic configuration in the present study was acceptable.

Table 1. Observed and expected number of meiotic configurations and $\chi 2$-values in five different translocated tip sterile lines of wheat based on non-random distribution of chiasmata.

\begin{tabular}{|c|c|c|c|c|c|c|c|c|c|c|c|}
\hline \multirow{2}{*}{$\begin{array}{c}\text { Lines / } \\
\text { Varieties }\end{array}$} & \multirow{2}{*}{$\begin{array}{l}\text { Observed }(\mathrm{O}) \text { and } \\
\text { Expected }(\mathrm{E})\end{array}$} & \multicolumn{6}{|c|}{ Meiotic configuration } & \multirow{2}{*}{ P-values } & \multirow{2}{*}{$\begin{array}{l}\text { No. of } \\
\text { cells } \\
\text { studied }\end{array}$} & \multirow{2}{*}{$\chi^{2}$-values } & \multirow{2}{*}{ Probability } \\
\hline & & I & $\mathrm{cII}$ & oII & cIII & cIV & oIV & & & & \\
\hline \multirow{2}{*}{ Kheri } & $\mathrm{O}$ & 0 & $41+6$ & 624 & $3 *$ & 4 & 28 & \multirow{2}{*}{0.9712} & \multirow{2}{*}{35} & \multirow{2}{*}{2.16} & \multirow{2}{*}{$0.75-0.50$} \\
\hline & $E$ & 0 & 38.65 & 626.70 & 0 & 3.69 & 31.14 & & & & \\
\hline \multirow{2}{*}{ Mexicani } & $\mathrm{O}$ & 0 & $35+6$ & 535 & $3 *$ & 5 & 22 & \multirow{2}{*}{0.9676} & \multirow{2}{*}{30} & \multirow{2}{*}{1.70} & \multirow{2}{*}{$0.75-0.50$} \\
\hline & $\mathrm{E}$ & 0 & 37.30 & 533.06 & 0 & 3.52 & 26.30 & & & & \\
\hline \multirow{2}{*}{ Pavon-76 } & $\mathrm{O}$ & 0 & $28+10$ & 542 & $5 *$ & 5 & 20 & \multirow{2}{*}{0.9685} & \multirow{2}{*}{30} & \multirow{2}{*}{2.47} & \multirow{2}{*}{$0.50-0.25$} \\
\hline & $\mathrm{E}$ & 0 & 36.27 & 534.09 & 0 & 3.43 & 26.39 & & & & \\
\hline \multirow{2}{*}{ Seri-82 } & $\mathrm{O}$ & 0 & $34+6$ & 631 & $3 *$ & 5 & 27 & \multirow{2}{*}{0.9721} & \multirow{2}{*}{35} & \multirow{2}{*}{1.32} & \multirow{2}{*}{$0.75-0.50$} \\
\hline & $\mathrm{E}$ & 0 & 37.43 & 627.89 & 0 & 3.59 & 31.25 & & & & \\
\hline \multirow{2}{*}{ Sonora-64 } & $\mathrm{O}$ & 0 & $39+4$ & 626 & $2 *$ & 4 & 29 & \multirow{2}{*}{0.9725} & \multirow{2}{*}{35} & \multirow{2}{*}{1.25} & \multirow{2}{*}{$0.75-0.50$} \\
\hline & $E$ & 0 & 36.89 & 628.43 & 0 & 3.54 & 31330 & & & & \\
\hline
\end{tabular}

$*=$ The III.I number is multiplied by 2 and added to the number of cIIs; all plants were analyzed with equation for non-random distribution of chiasmata.

Table 2. Observed and expected number of meiotic configurations and $\chi^{2}$-values in five different translocated tip sterile lines of wheat based on random distribution of chiasmata.

\begin{tabular}{|c|c|c|c|c|c|c|c|c|c|c|c|}
\hline \multirow{2}{*}{$\begin{array}{l}\text { Lines / } \\
\text { Varieties }\end{array}$} & \multirow{2}{*}{$\begin{array}{l}\text { Observed }(\mathrm{O}) \text { and } \\
\text { Expected }(\mathrm{E})\end{array}$} & \multicolumn{6}{|c|}{ Meiotic configuration } & \multirow[b]{2}{*}{ P-values } & \multirow{2}{*}{$\begin{array}{l}\text { No. of } \\
\text { cells } \\
\text { studied }\end{array}$} & \multirow[b]{2}{*}{$\chi^{2}$-values } & \multirow[b]{2}{*}{ Probability } \\
\hline & & I & cII & oII & cIII & cIV & oIV & & & & \\
\hline \multirow{2}{*}{ Kheri } & $\mathrm{O}$ & 3 & 41 & 6.24 & 3 & 4 & 28 & \multirow{2}{*}{0.9712} & \multirow{2}{*}{35} & \multirow{2}{*}{79.35} & \multirow{2}{*}{$\mathrm{P}<0.05$} \\
\hline & $\mathrm{E}$ & 1.20 & 37.31 & 627.25 & 0.11 & 3.69 & 31.14 & & & & \\
\hline \multirow{2}{*}{ Mexicani } & $\mathrm{O}$ & 3 & 35 & 535 & 3 & 5 & 22 & \multirow{2}{*}{0.9676} & \multirow{2}{*}{30} & \multirow{2}{*}{72.61} & \multirow{2}{*}{$\mathrm{P}<0.05$} \\
\hline & $E$ & 1.32 & 35.86 & 533.66 & 0.12 & 3.52 & 26.30 & & & & \\
\hline \multirow{2}{*}{ Pavon-76 } & $\mathrm{O}$ & 5 & 28 & 542 & 5 & 5 & 20 & \multirow{2}{*}{0.9685} & \multirow{2}{*}{30} & \multirow{2}{*}{233.16} & \multirow{2}{*}{$\mathrm{P}<0.05$} \\
\hline & $\mathrm{E}$ & 1.25 & 34.89 & 534.66 & 0.11 & 3.43 & 28.14 & & & & \\
\hline \multirow{2}{*}{ Seri-82 } & $\mathrm{O}$ & 3 & 34 & 631 & 3 & 5 & 27 & \multirow{2}{*}{0.9721} & \multirow{2}{*}{35} & \multirow{2}{*}{88.94} & \multirow{2}{*}{$\mathrm{P}<0.05$} \\
\hline & $E$ & 1.14 & 36.18 & 628.41 & 0.10 & 3.59 & 33.07 & & & & \\
\hline \multirow{2}{*}{ Sonora-64 } & $\mathrm{O}$ & 2 & 39 & 626 & 2 & 4 & 29 & \multirow{2}{*}{0.9725} & \multirow{2}{*}{35} & \multirow{2}{*}{37.33} & \multirow{2}{*}{$\mathrm{P}<0.05$} \\
\hline & $\mathrm{E}$ & 1.11 & 35.67 & 628.93 & 0.10 & 3.74 & 31.31 & & & & \\
\hline
\end{tabular}

All plants were analyzed with equation for random distribution of chiasmata. 


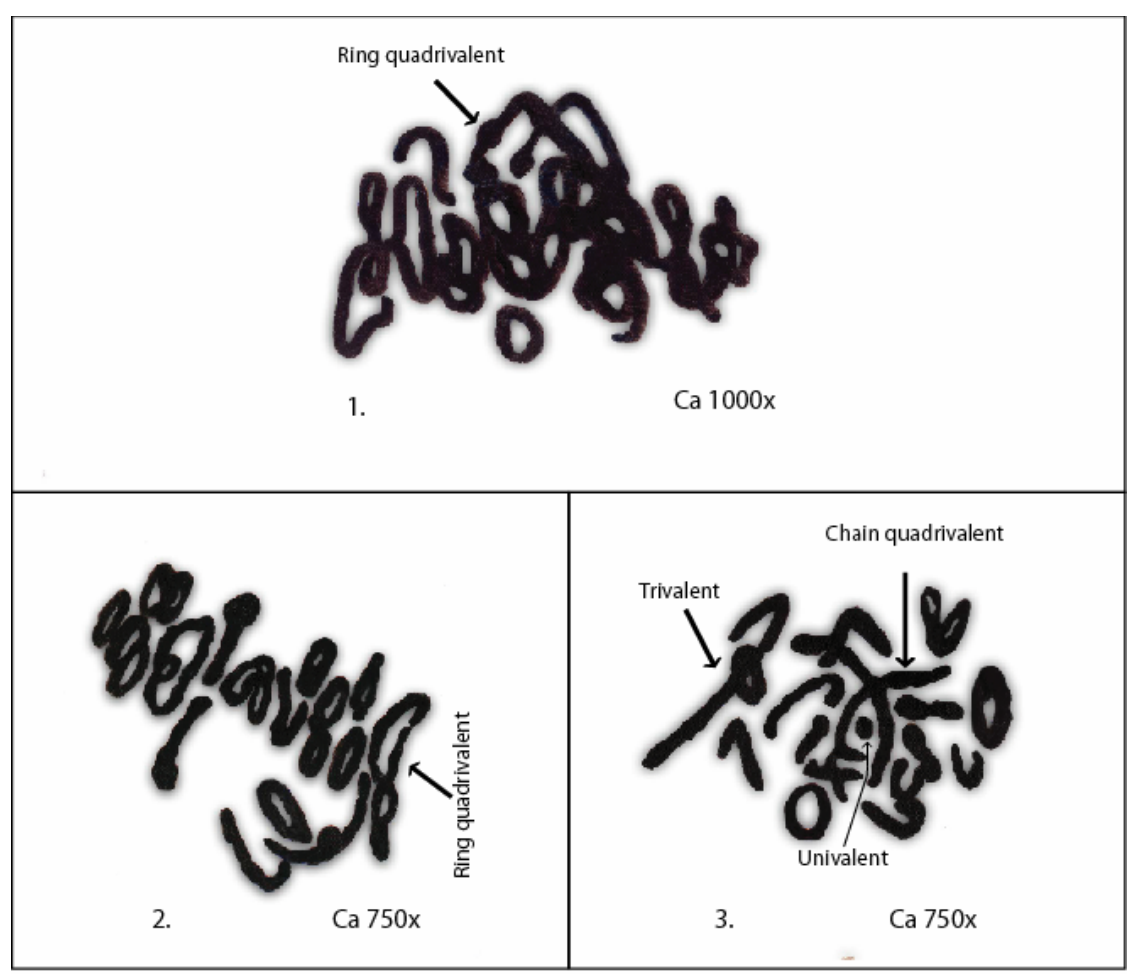

Figs. 1-3. Camera Lucida drawings of meiotic configurations in PMCs of translocated lines or varieties of hexaploid wheat.

In this study, interchange of segments between two nonhomologous chromosomes in five tip sterile lines/varieties of wheat were found to produce cross shaped configurations of quadrivalent at diakinesis stage of meiosis. The true existence of quadrivalent in hexaploid wheat is evidenced in last two decades of twentieth century. Vega and Lacadena (1982) detected quadrivalents in hybrids of Chinese Spring monosomic wheat and Mentana. Elliott (1985) reported it in a cross between Atlas 66 and Wichita of wheat. Later on Brears et al. (1988) and Schiegel and Schiegel (1989) reported similar findings. In 1990, Sandra et al. made cytogenetic studies on heterozygous reciprocal translocation in hexaploid wheat. Different types of meiotic configurations due to reciprocal translocation in wheat (Triticum aestivum L.) were reported by Primard et al., (1991), Gupta and Gupta (1991), Merker (1992), Kawahara et al., (1993) and Berzonsky (1993, 1996). Among the configurations ring quadrivalent (oIV), chain quadrivalent (cIV) and trivalent plus univalent (III.I) were observed clearly.

However, data on different meiotic configurations such as oIV, cIV, III.I, oII, cII and I were analysed quantitatively following the model and equations proposed by Jackson and Murray (1986). They derived two different models for chromosomes pairing and chiasma distribution. Their first model represented the normal condition and assumed complete synapses of homologous bivalents and the arms of interchange quadrivalents. That was followed by a non-random distribution of chiasmata among bivalents and multivalents. Their second model assumed that a hologenomic mutation involves all chromosomes of a genome to be equally affected. Meiotic configurations in the present study were same at diakinesis and metaphase I stages. Bivalent or bivalent equivalents always had at least one chiasma and univalents occurred only as part of III.I configuration. These configurations involving four chromosomes always showed exchange of the part of chromosomes, not whole arm. This is why, their (Jackson and Murray, 1986) first model was followed for making quantitative analysis of the translocation heterozygotes in five tip sterile lines of hexaploid wheat in the present study.

The data presented in Table 1 revealed good agreement between numbers of expected and observed meiotic configurations. All the plant samples had a good fit to the Ho with $\mathrm{P}>0.05$. This agreement between the observed and expected values for different meiotic configurations of heterozygotes proved accuracy of the 
equations for the model system given by Jackson and Murray (1986). However, there may be questions that how will translocation involving a segment of chromosome affect the configuration frequencies. The answer may be that it depends upon the genetic system i.e. if chiasmata are localized in the distal part, a translocation involving that part only might be sufficient for expected results. Anyhow, this situation is apparently different in some cases of diploid translocation heterozygotes analyzed by Sybenga (1970) in different context showing a good fit for the values expected by Jackson and Murray's equations in 1983. However, many other examples given by Sybenga (1970) had many oII configurations to the present expected values and this might be due to occurrences of many more proximal chiasmata.

The observed and expected numbers of meiotic configurations obtained in the present study were also analysed, when the equations were based on random pairing and/or chiasma distribution. But findings here differed significantly from those obtained with nonrandom chiasma distribution. Here the chi-square $\left(\chi^{2}\right)$ values for random expected numbers were not in fit due to $\mathrm{P}<0.05$. Therefore, non-random expected number of meiotic configurations was found to be expectable in the present study. However, Jackson and Murray (1986) obtained $\chi^{2}$ values for non-random expected number with $\mathrm{P}>0.10$ and for random expected number with $\mathrm{P}>0.05$ and chose the non-random fit.

A few interchanges that were unequal in the present study could yield more III.I configurations and quadrivalents could be reduced below expectations. But in fact, quadrivalents were in frequent, higher than III.I and much lower than oII configurations. However, Haq (2002) reported bivalent with less frequency compared to that of quadrivalents. She found four types of quadrivalents viz. ring, chain, pliers shaped and Xshaped with the preponderance of bivalents. She just calculated their frequencies only and did not make any quantitative analysis. However, the testing of mathematical models and equations that predict chromosome association in diploid species, hybrids and in autopolyploids (Jackson and Casey, 1982; Jackson and Hauber, 1982; Jackson, 1984 and Murray et al., 1984), it may also be considered possible to predict meiotic association in allohexaploid wheat (which normally exhibits bivalent chromosome pairing) following the models and equations proposed by Jackson and Murray (1986). Being allohexaploid Triticum aestivum shows regular bivalent formation at meiosis because of the ph loci and always this species acts as functionally diploid. From that point of view the mentioned models and equations were used for making meiotic analysis in this functionally diploid species. The presence of quadrivalents in these wheat species obviously indicates the heterozygous reciprocal chromosomal translocation and its orientation at meiosis may produce aneuploid and duplicate deficient gametes. Although it is believed that genetic consequences of heterozygous reciprocal chromosomal translocation in wheat may tolerate aneuploidy, but its byproduct can cause sterility (Suarez and Artega, 1990). This is why, it was essential for making a quantitative analysis of meiotic configurations in these five apical sterile lines of hexaploid wheat which exhibited chain and ring quadrivalents due to heterozygous reciprocal chromosomal translocation.

Acknowledgements: The authors would like to acknowledge Late Dr. Entajul Haque, former Principal of Gul-Gafur Girls High School and College, Baliaghata, Godagari, Rajshahi for his flawless interest to this work and unconditional support.

\section{References}

Baker EP and McIntosh RA. 1966. Chromosome translocation identified in varieties of common wheat. Can. J. Genet. Cytol. 8: 592-599.

Baier AC, Zeller EJ and Fischbeck G. 1974. Identification of three chromosomal interchanges in common wheat. Triticum aestivum L. Can. J. Genet. Cytol. 16: 349-354.

Berzonsky WA. 1993. Detection of quadrivalents in the Brazillian wheat 'Frondoso'. Wht. Int. Serv. 77: 19-22.

Berzonsky WA. 1996. Brazilian origin and inheritance of a heterozygous reciprocal chromosome translocation in wheat (Triticum aestivum L.). Cytologia 61: 253-258.

Brears T, Hydon AG and Bingham J. 1988. An assessment of the feasibility of producing $F_{1}$ and $F_{2}$ hybrids for the UK. $7^{\text {th }}$ Int. Wheat Genet. Symp. pp. 1057-1062.

Coucoli H and Skorda E. 1969. Further evidence of the interchange condition of wheat. Osterr. Bot. Z. 116: 119-126.

Elliott M. 1985. Chromosomal locations of genes for aluminum tolerance, leaf rust [resistance], and high protein in the wheat cultivar 'Atlas 66' using the monatomic method. Ph.D. dissertation, University of Nebraska, Lincolin, NB. Diss. Abstr. Int. B. 47(1): 3-5.

Gupta PK and Gupta SN. 1991. Cytogenetics of chromosome interchanges in plants. In: Chromosome Engineering in Plants: Genetics, Breeding, Evolution, Part-A, pp. 87-112 (eds. Gupta PK and Tsuchyia T), Elsevier Science Publ., NY, USA.

Haq S. 2002. Heterozygous reciprocal translocation in wheat (Triticum aestivum L.). MPhil. Thesis. Dept. of Botany, University of Rajshahi, Bangladesh.

Jackson RC. 1984. Chromosome pairing in species and hybrids. In: Plant Biosystematics (ed. Grant WF), pp. 67-86. Academic Press, Canada. 
Jackson RC and Casey J. 1982. Cytogenetic analyses of autopolyploids: Models and methods for triploids to octoploids. Am. J. Bot. 69: 487-501.

Jackson RC and Hauber DP. 1982. Autotetraploid and autotriploid cytogenetic analyses: correction co-efficient for proposed binomial models. Am. J. Bot. 69: 644-646.

Jackson RC and Murray BG. 1983. Colchicine induced quadrivalent formation in Helianthus: Evidence of ancient polyploidy. Theor. Appl. Genet. 64: 219-222.

Jackson RC and Murray BG. 1986. Quantitative analysis of diploid translocation heterozygotes: test of models and equations. Theor. Appl. Genet. 71: 600-606.

Kawahara T, Nevoe E and Beiles A. 1993. Frequencies of translocation in Israeli populations of Triticum dicoccides, Korn. Evol. Biol. 23: 217-246.

Lange W, Lawrsent L, Larsen J, Junberg L, and Ellestrom A. 1987. Cytogenetic analysis of structural rearrangements in three varieties of common wheat, Triticum aestivum. Theor. Appl. Genet. 73: 635-645.

Law CN, and Worland AJ. 1973. Aneuploidy in wheat and its uses in genetic analysis. Ann. Report for 1972, pp. 25-65. P.B.I. Cambridge.

Merker A. 1992. The production of a 5B-5R chromosome translocation for indcution of homoeologus meiotic pairing in wheat. Hereditas-Landskron. 117(1): 61-66.

Murray BG, Sieber VK and Jackson RC. 1984. Further evidence for the presence of meiotic pairing control genes in Alopecurus L. (Gramineae). Genetica 63: 13-17.

Perera E, Lacadena JR and Sendino AM. 1983. Cytogenetic structure of durum wheat cultivars from, or introduced into Spain. Z. Pflanzenzucht 91: 36-45.
Primard SJ, Morris R and Papa CM. 1991. Cytogenetic studies on a heterozygous reciprocal translocation in the wheat (Triticum aestivum L.) cultivar Atlas 66. Genome 34(3): 313-316.

Sandra JP, Morris R and Papa CM. 1990. Cytogenetic studies on a heterozygous reciprocal translocation in the wheat (Triticum aestivum L.) cultivar Atlas 66. Genome 34: 313-316.

Schiegel G and Schiegel R. 1989. A compendium of reciprocal intervarietal translocations in hexaploid wheat. Kulturpflanze 37: 163-176.

Suarez EY and Arteaga M. 1990. Influence of meiotic abnormalities on grain condition in a commercial hybrid wheat. Cereal Res. Com. 18: 27-31.

Sybenga J. 1970. The effect of reciprocal translocation on segregation and multivalent formation in autotetraploids of rye, Secale cereale. Genetica 44: 270-282.

Sybenga J. 1975. The quantitative analysis of chromosome pairing and chiasma formation based on the relative frequencies of MI configurations. VII. Autotetraploids. Chromosoma 50: 211-222.

Vega C and Lacadena JR. 1982. Cytogenetic structure of common wheat cultivars from or introduced into Spain. Theor. Appl. Genet. 61: 129-133.

Vega C and Lacadena JR. 1983. Identification of two chromosomal interchanges in cv. "Canaleja" of common wheat, Triticum aestivum L. Euphytica 32: 485-491.

Manuscript received on 9 June 2011 and revised on 10 October 2011 